\title{
Assessing for Learning: Teacher Training in Practice Involving 14 Postgraduate Certificate in Education (PGCE) Students
}

\author{
Elize (E. C.) du Plessis \\ University of South Africa, Pretoria, South Africa \\ https://orcid.org/0000-0003-4299-4632
}

\begin{abstract}
In this age of answerability, assessment is a dominant factor that can either promote or weaken learners' education internationally. Yet many of the usual practices followed by institutions show that assessments in the classroom continue to be a challenge for teachers. This signifies that assessment is either not well understood or not done effectively during all stages of education. The study reported in this article attempted firstly to detect how prepared teachers were to perform assessments for learning, and secondly to enhance teachers' assessment practices. It focused on the qualities of good assessment practices, different methods of assessment, types of assessment, and feedback and assessment to enhance learning in the classroom. A qualitative approach was used, involving 14 participants who had completed a postgraduate certificate in education (PGCE) at a distance teaching institution. Results revealed inter alia a need for longer teaching practice periods, the use of taxonomies on different cognitive levels, and subject-specific workshops. It is recommended that more practical examples, like lecture videos, taxonomies, and rubrics, should be employed, and assessment processes should embrace technology.
\end{abstract}

Keywords: assessing for learning; feedback; teacher training; teaching practice; types of assessment

\section{Introduction and background}

Student learning and success depend largely on the critical role of teachers, who need to use thoughtful, distinguished assessment methods, intensive feedback, and pure reporting strategies to support learning. The main purpose of assessment is to improve learners' learning and teachers' teaching as both react to the facts made available (Friesen et al., 2015). Assessment, teaching, and learning are intimately related as they support one another. Assessment is a dominant practice that can both improve or constrain learning, depending on how it is initialised (Ministry of Education, 2020). 
Instructional activities may determine assessments categories. The concept classroom assessment is used to express assessments intended or selected by teachers and is given as a vital activity of classroom instruction (Pellegrino, 2014). Classroom assessment is given throughout the teaching and learning process. This classification of assessments may comprise teacher-learner collaborations in the classroom, opinions, learners' tasks that result directly from continuing instructional events (called 'immediate assessments'), and questions that are narrowly interwoven to instructional actions (called 'close assessments') (Pellegrino, 2014). Classroom assessment may also consist of official classroom examinations, which contain the content of one or more learning components (called 'proximal assessments') (Pellegrino, 2014; Ruiz-Primo et al., 2012). This classification may similarly contain assessments that are formed by curriculum designers and rooted in training resources for teacher use (Andrade \& Cizek, 2010). According to De Luca et al. (2019), there has been a global trend towards increased accountability and assessment in schools over the past several decades. While the researcher asserts the relevance and importance of understanding assessment capability, it must be connected within teacher education programmes.

Assessment for learning is a procedure whereby assessment evidence is used by teachers to change their teaching approaches, and through which learners change their learning tactics. In addition, assessment for learning must be reinforced by providing the greatest assurance that each student can make good progress. It should be focused on the concept "to teach and to learn". Assessment for learning should empower shared learning, where teachers and learners share and value one another's contribution (Alberta Education, 2008; McNamee \& Chen, 2005).

But how prepared are teachers to provide effective assessment? According to the Department of Basic Education (DBE), the

"... matric class of 2019 achieved a pass rate of $81.3 \%$, up from $78.2 \%$ in 2018. But the number should be seen in context. In 2017, a total of 1052 080 learners were enrolled in grade 10, yet only 409906 learners eventually passed matric last year. The results show that $44.55 \%$ of Matrics that [who] passed, passed with a grade high enough for admission to bachelor's degrees." (South Africa's Education Statistics, 2020).

The Council for Quality Assurance in General and Further Education and Training (Umalusi), works closely with the DBE. Umalusi provides accredits of education and training. The key roles of Umalusi are to set assessment standards for qualifications on the General and Further Education and Training Qualifications Framework, and to certify that assessment for accreditation in schools, further education and training colleges and adult education and training centres is of the essential standard.

In the quality assurance report of the DBE November 2019 National Senior Certificate (NSC) Examinations and Assessment, Umalusi pointed out that there was sufficient distribution of cognitive levels across the main stream related to the subjects tested for school-based assessment (SBA) moderation, as prescribed by 
the Curriculum and Assessment Policy Statement (CAPS) (Umalusi, 2020). The bulk of Geography learners did well in the lower- and middle-order questions, but only a few could succeed in the higher-order questions. In most sampled schools, there was very little to no proof that teachers made use of grids to examine the cognitive request and stages of difficulty when setting internal tasks to ensure that they were of the required standard. The assignment tasks used in Accounting concentrated more on lower cognitive levels. Mathematics assessment tasks were confined to questions that promoted higher cognitive level thinking, although learners in some schools struggled with level 1 questions. Regarding Life Orientation, the examination question paper did not provide for assessing learners' problem-solving skills (Umalusi, 2020).

Thus, the main research question was: how prepared are teachers to provide assessment for learning? The objectives included determining what types of assessment teachers used and if there was a lack in assessment training.

\section{Conceptual framework}

The conceptual framework addressed interrelated concepts such as qualities of good assessment practices, different methods of assessment, types of assessment and feedback, classroom assessment, and assessment to enhance learning in the classroom.

\subsection{Qualities of good assessment practices}

Research shows that excellence in assessment influences the levels of student learning, student efficiency and learner commitment (NVSD, 2018). The NVSD Curriculum Hub identifies ten main beliefs of assessment that complement and reinforce policies. These beliefs are:

1) evaluation and assessment activities should be in line with crucial curricular concepts, content, expectations and learning outcomes.

2) assessment ways and means must be suitable for and well-matched with the aim and environment of the assessment.

3) formative assessment (aimed at learning) must be continuous, diverse, and dominant to the learning sequence.

4) formative assessment (by way of learning) includes learners in setting individual objectives for learning and observing their improvement by doing self-assessment.

5) learners should receive ongoing comments that are clear, precise, and timely to support their development on the way to accomplishing learning outcomes.

6) summative assessments must be grounded in suitable benchmarks (align to main abilities and learning criteria), and contain a variation of methods for learners to show their learning.

7) assessment procedures should be distinguished to accommodate learners' various requirements, learning styles and interests.

8) appraisal and rating must mirror accomplishment and growth over time in relation to exact learning criteria or learner objectives; evaluation is not linked to behaviour and attitude, but to learning. 
9) feedback to learners must be precise and continuing, with an emphasis on achieving standards-based language and significant explanations and demonstrations of scholarship.

10) reporting and assessment practices and procedures should encourage all learners, including those with special educational needs and those who are learning a second or additional language (NVSD 2018).

Following from these beliefs, good assessment practices include selecting assessment techniques for your subject or programme, and are at the core of curriculum design. Figure 1 illustrates the possibility of assessing learners by means of an integrated course design model, where well-known learning goals are reinforced by suitable learning activities and assessment means (Fink, 2003). The elementary segments in this framework of integrated course design are similar to those found in other models of instructional design: scrutinising the contextual influences; verbalising the learning objectives; planning the feedback and assessment processes; and choosing teaching/learning activities. What is unique about this model is the interrelatedness of these segments.

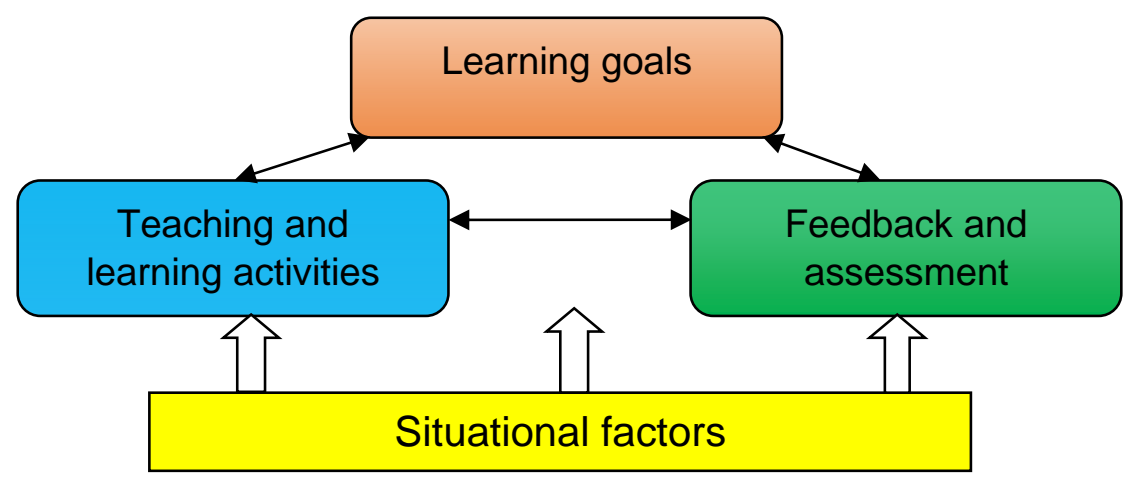

Figure 1: The key components of integrated course design (Fink, 2003)

The teaching/learning activities must be aligned with the learning goals. The learners must not only learn from the content or the teacher - they need to practise and be provided with feedback in order to learn how to reason, critically.

\subsubsection{Learning goals}

It is important to formulate learning goals at the start of the course design procedure. The importance of the subject or programme for the learners must be determined. Clear, specific and well-defined goals should be aligned with the aim and the subject methodology (Fink, 2003, Author, 2020).

\subsubsection{Teaching and learning activities}

Activities should include a short-term explanation of teaching strategies, such as the grouping and order of teaching/learning activities. Activities should include creative exercises (Fink, 2003). 


\subsubsection{Feedback and assessment}

The following components must be observed when planning a suitable assessment technique that will reproduce the established learning objectives and actions: reliability, standardisation, validity and practicality.

Reliability refers to the degree to which the assessment can be depended upon to be accurate. Standardisation launches a fixed preference, thus increasing the reliability of an assignment, test or project. Validity is described as the degree to which the instrument measures what it sets out to measure. Teachers must detect the expected learning outcomes of the subject or programme in order to assess learners' work suitably. Practicality states the act of the assessment manner and its application to all the learning objectives of the subject or programme (Miller, in Algonquin College, 2019, Elton, 2002).

\subsection{Different methods of assessment}

Assessment methods must be suitable and exclusive for particular assessment outcomes and for the assessment of different subjects. Possible assessment methods are: concealed examinations; arranged or free, with or without selection of questions; open-book assessments; examinations with complex facts about questions; single-question unknown papers; multiple-choice/objective tests; coursework assessment; oral examination; self-assessment and peer assessment; and group assessment (Elton, 2002). Assessment should be more than merely collecting proof of how well the learners have reached the objectives; it should also facilitate the planning of improved teaching and learning in the next cycle.

\subsection{Types of assessment and feedback}

Learners want regular feedback on exactly how they are doing. If they are deprived of regular feedback, they cannot progress in a concentrated manner to meet the learning outcomes (Algonquin College, 2019, Booyse et al., 2020). Feedback can take different forms. It can be delivered as a distinct entity, such as informal feedback about a learner's comprehension of a notion in class, or as a combination of numerous entities, such as formal, formative and peer feedback. Different types of feedback should be encouraged to improve learning and to create different opportunities for growth (Federation University, 2019, Khan, 2019).

\subsubsection{Formative assessment}

Formative assessment is a crucial part of teaching and learning. It does not contribute to the final marks allocated to a unit; it rather monitors learning to provide ongoing feedback that can help learners identify their strengths and weaknesses and help them to improve; it also prevents them from repeating the same mistakes (Federation University, 2019; Khan, 2019). Booyse et al. (2020, p. 109) describe formative assessment as "a process: one in which information about learning is evoked and then used to modify teaching and learning activities".

\subsubsection{Summative assessment}

The objective of summative assessment is to assess learning at the conclusion of a task by measuring it against some scale. Consequently, summative feedback contains comprehensive remarks that are linked to precise aspects of the learners' 
work. It clarifies how the mark has been determined based on the measures provided, and it may include supplementary practical remarks on how the work could be amended (Federation University, 2019; Khan, 2019).

\subsubsection{Diagnostic assessment}

Like formative assessment, diagnostic assessments aim to improve learners' knowledge. Moreover, they work in a recessive manner, rather than looking to the future. A diagnostic assessment determines what the learner knows, and evaluates the learning problems faced by the learner (Khan, 2019; Booyse et al., 2020). Not diagnosing these problems could limit the learner's contribution to learning.

\subsubsection{Dynamic assessment}

Dynamic assessment evaluates what learners can accomplish when unknown topics are taught. It determines how learners, who do not have any previous knowledge, embrace it (Khan, 2019). Dynamic assessment may be used to evaluate the potential of learners who have a largely disadvantaged background, and generally takes place before the core teaching commences (Khan, 2019).

\subsubsection{Synoptic assessment}

Synoptic assessment contributes to the self-assurance of learners to combine sections of their learning from diverse fragments of a design, and to demonstrate their developed knowledge of the concept (Khan, 2019). Therefore, it supports in determining how to relate knowledge to comprehend a concept (Khan, 2019).

\subsubsection{Criterion-referenced assessment}

Specific criteria are used to evaluate the achievement of every learner. Other learners' achievements or performance should not be taken into account. Furthermore, the teacher should evade normative thinking because it can affect their decision. The teacher should also ensure trustworthiness and legitimacy (Khan, 2019).

\subsection{Classroom assessment}

Assessment is crucial in teaching-learning progression. It mediates learning and improves tuition, and can involve different assessment methods. Classroom assessment is usually separated into three categories: assessment for learning; assessment of learning; and assessment as learning.

\subsubsection{Assessment for learning (formative assessment)}

Assessment for learning means that assessment and teaching are combined to form one entity. The strength of this type of assessment derives from identifying the amount of learning that takes place in the mutual academic activities of the school day - and how much comprehension into learning, teachers can pit from this (McNamee \& Chen, 2005).

Furthermore, assessment for learning entails continuous assessment that allows teachers to observe learners daily and adapt their tuition based on what the learners need in order to be successful. Subsequently, when teaching a lesson, it should be determined whether the lesson was manageable for all the learners, in 
addition to being challenging for more gifted learners. What the learners have learned and still need to know, must also be established. Decisions are needed on how to improve the lesson to make it more current, and, if needed, what other lesson might be offered as an improved substitute. This frequent valuation is at the core of refining teaching for learning (Burns 2005). This concept is further discussed in section 3 of this article, which deals with the theoretical framework.

\subsubsection{Assessment of learning}

Assessment of learning means to summarise learning, and the subsequent stage of growth after a period of work, by allocating a mark to responses in an assessment or examination. It provides evidence of learner accomplishments. Since it provides valuable feedback, it has a slight consequence on learning (Alberta Education, 2008).

\subsubsection{Assessment as learning}

Assessment as learning improves learners' metacognitive skills. This form of assessment assists learners in becoming lifetime pupils. As learners employ peer assessment and self-assessment, they learn to understand information, to revisit previously understood knowledge, and to use it for future learning. Learners grow a common sense of proprietorship and value when they practise teacher, and peer and self-assessment feedback, so as to adjust and improve upon their understanding of subject matter (Alberta Education, 2008).

\subsection{Assessment to enhance learning in the classroom}

As feedback is an important component of many educational programmes, it is important to follow up with interventions (Booyse et al., 2020; Frey, 2018). Teachers need to pay attention to what individual learners think and know, and construct effective practices in light of these thoughts and knowledge. Teachers must know and understand their content to ensure that they deliver important and suitable feedback, which will assist each individual learner in progressing through the curriculum levels (Friesen et al., 2015).

It is important that classroom assessment should support learning, since learning is the essential action in the teaching-learning setting. (Booyse et al., 2020). More and more research proposes that a critical feature of effective classroom-based (formative) assessment, is the alliance of assessment undertakings with objectives concentrated on learning (Ayala et al., 2008; Van der Nest et al., 2018; Wiley, 2008). Formative assessment can be seen as an orderly procedure during which proof is collected and feedback about learning is constantly provided during the teaching process (Van der Nest et al., 2018). This feedback sheds light on the gap between a learner's present level of learning and the desired learning objectives. It is important that teachers should understand the learning objectives and align their classroom activities with these objectives and the assessment standards, and then compare their learners' development to the set objectives (Shepard, 2000; Van der Nest et al., 2018). Unfortunately, teachers are often poorly prepared for classroom assessment during their teacher training, and in-service teachers often point to the fact that they need additional professional development in classroom-based assessment (DeLuca \& Klinger, 2010). Classroom assessment entails considerably more than just assessing learning outcomes. 


\section{Framing assessment for theoretical learning}

A theoretical framework is an outline that offers guiding principles for the study. Ngulube (2018) notes that the theoretical framework is the adhesive that links the research devices, and when the theoretical framework is absent, the research design falls apart. The theoretical framework used in this research is based on the UK's National Foundation For Educational Research Report (NFER, 2007), which sets out assessment for learning.

Assessment for learning should incorporate and use different methodologies. These can include everyday activities, such as learning discussions; reflection; learners' self-assessment and peer assessments; a thorough enquiry of a learner's work; and assessment techniques, which might be transcribed items, planned interview questions, or items teachers formulate themselves. The form of the assessment is not the most important factor; more important is the way in which the information collected is used to advance teaching and learning (NFER, 2007, Ministry of Education, 2020).

\subsection{What is assessment for learning?}

Feedback is generated by assessment for learning (AFL) as a teaching and learning methodology that can be used to increase learners' success. AFL wishes to 'close the gap' between a learner's present situation and where they want to be in their learning and achievement. Expert teachers design academic activities that help learners to do this. AFL involves learners becoming more involved in their learning, gaining confidence, and starting to 'think like a teacher' (NFER, 2007). AFL requires learners to reason more vigorously about their current situation and where they are going and how they can get there (see figure 2).

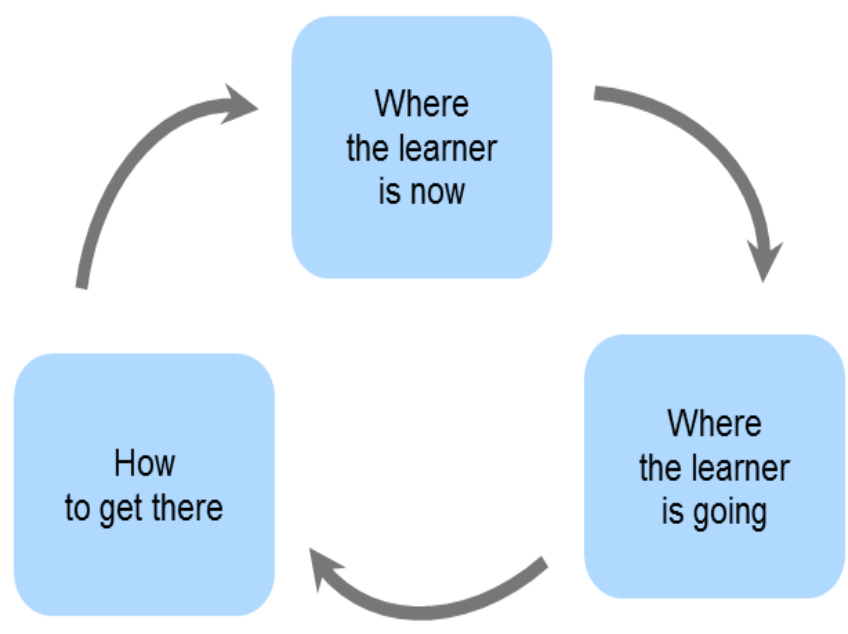

Figure 2: Assessment for learning (NFER, 2007)

Good teachers incorporate AFL into their instruction as a normal part of teaching, and can decide how often to use the technique to achieve maximum impact. AFL helps to make understanding and knowledge 'more visible' (Hattie, 2016) to learners. 


\subsection{Assessment for learning and the connection with formative and summative assessment}

AFL has traditionally been regarded as formative assessment, because asking questions and giving feedback can assist learners in adapting or planning their learning. Summative assessment, on the other hand, is typically done to evaluate learner accomplishment at the completion of a period of learning.

Table 1, which is grounded on the UK's National Foundation For Educational Research Report (NFER, 2007), categorises different types of formative and summative assessment into formal assessments and informal assessments.

Table 1: Types of formative and summative assessment (NFER, 2007)

\begin{tabular}{|c|c|c|}
\hline & $\begin{array}{c}\text { Formative } \\
\text { Assessment }\end{array}$ & $\begin{array}{l}\text { Summative } \\
\text { Assessment }\end{array}$ \\
\hline Informal & $\begin{array}{l}\text { Questioning } \\
\text { Feedback } \\
\text { Peer assessment } \\
\text { Self-assessment }\end{array}$ & $\begin{array}{l}\text { Essays in uncontrolled conditions } \\
\text { Portfolios } \\
\text { Coursework } \\
\text { Teacher assessment }\end{array}$ \\
\hline Formal & $\begin{array}{l}\text { Further analysis or tests, exams, } \\
\text { essays } \\
\text { Target setting }\end{array}$ & $\begin{array}{l}\text { Tests } \\
\text { Exams } \\
\text { Essays in controlled conditions }\end{array}$ \\
\hline
\end{tabular}

All the assessment methods in table 1 support AFL because their main aim is to assist learners to improve their learning. In AFL, it is the aim of assessment, rather than the nature of it, that is imperative (Hattie, 2016).

\section{Method}

A constructivist paradigm was relevant to the study as it allowed the researcher to determine the preparedness of teachers to execute assessment effectively. It is clarified by Mertens (2010) that qualitative data collection methods, such as interviews, observations, document reviews and open-ended questionnaires, are leading in the constructivist paradigm, which has the purpose to understand the multifaceted domain of the participants. By undertaking an interpretive enquiry, the researcher aimed to interpret, describe and report on the reflections and lived experiences of those teachers who participated in the research (Schwartz-Shea \& Yanow, 2020). These teachers were Intermediate, Senior and Further Education and Training teachers.

Purposive selection was performed to select 14 knowledgeable participants. The criteria were that they had to have a minimum of five years' teaching experience and must have completed the PGCE programme. Data collection was done by sending questionnaires via e-mail to the participants, which was in line with the distance education mode of delivery of this institution.

An extensive literature study aided the construction of a questionnaire. Ten openended and closed-ended questions were asked; these were restricted for the 
purpose of gathering demographic facts and improving the qualitative data. The following questions were asked in the questionnaire (See Appendix A):

1. Biographic information (see table 2)

2. What is lacking in your assessment training, for example how to deal with discipline/multigrade classes/diversity/technology?

3. Give three examples of improper and inappropriate assessment.

4. Are you aware of the assessment policy and how familiar are you with it?

5. How is learners' academic work assessed?

6. Give one example of how you used assessment to enhance learning in your classroom (at any level or on any topic). Explain how you planned to conduct this assessment and how you intended the session to help children to learn from the assessment. Describe the steps you followed and how the assessment played out in the classroom.

7. Note in detail your discussions with learners about the assessment and their performance. Describe what you said, how they responded and the discussions about the test in class among the children.

8. What is assessment for learning about? How should it be used in your subject? (Please give your own views and reflections.)

9. Are there any other issues you wish to raise or comments and recommendations with regard to assessment you wish to make?

10. Do you have any recommendations regarding university training for student teachers in order to equip and prepare them to enter the teaching profession after they have completed their qualification?

The transcribed data collected from the questionnaires were analysed by means of inductive analysis, which involves a procedure during which qualitative researchers summarise and make sense of the data (McMillan \& Schumacher 2014; Oltmann 2016). The researcher first looked at particular data, and then identified categories and patterns. The latter was used to establish the overall themes emerging from the collected data and by making deductions.

Trustworthiness of a study is ensured when findings of the research study provide the desired answers, and contribute to an understanding of, and improve upon, the specific phenomenon. Olivia (2017) posits that trustworthiness exist when the research study's discoveries are credible, transferable, confirmable and dependable.

Ethical issues were addressed by applying for ethical clearance from the institution. Participants were given the freedom to choose to participate or not, without having to fear that non-participation would have negative consequences. Anonymity was guaranteed. The biographical data of participants (see question 1 on the questionnaire) are presented in table 2.

Table 2: Biographical data of the participants $n=14$

\begin{tabular}{|l|r|r|r|r|}
\hline AGE & $\mathbf{2 5 - 3 0}$ & $\mathbf{3 1 - 4 0}$ & $\mathbf{4 1 - 5 0}$ & $\mathbf{5 0 +}$ \\
\hline MALES & 1 & 2 & 1 & 1 \\
\hline FEMALES & 2 & 4 & 3 & \\
\hline TOTAL & 3 & 6 & 4 & 1 \\
\hline
\end{tabular}


As shown in table 2, there were five male and nine female participants, ranging in age from 26 to 54 years.

\section{Findings and discussion}

The research findings are in line with the research objectives. Five main themes were identified in the categories emerging from the empirical data. The findings are presented under the identified themes, which first reproduced the expressions of the participants in the form of precise quotations, and thereafter, the data were interpreted and linked to the literature and the theoretical framework.

\subsection{Theme 1: Valuation of assessment training}

Only two of the 14 participants felt that nothing had lacked in their training. 12 participants expressed concerns that their training had been lacking. A 49-yearold female remarked that she needed assistance with the use of Bloom's taxonomy. According to a 34-year-old female participant, "The time arranged for the CAPS Assessment training is usually not enough and it is only once per term. As educators we face the challenge of teaching new subjects every year and are expected to cope without formal training in assessment in the new subject."

A 34-year-old male participant asked for "frameworks to set assessment within different subjects and not only generic frameworks. Especially higher-order thinking and different cognitive reasoning skills".

A 54-year-old male emphasised the value of technology by stating that "issues lacking in my assessment training has been how to integrate technology in assessments as well as how to deal with issues of diversity". Training in the use of technology was pointed out by three more participants.

All the participants indicated that they were aware of the assessment policy and familiar with it. They stated that it was in line with the CAPS document and other assessment documents, and that they used it in their teaching.

Based on the views of the majority of participants, it seems that they felt confident about the assessment training they had received. However, it was also clear from the findings that they needed assistance with taxonomies (making use of different cognitive levels), subject-based assessment training, and training in the use of technology.

Literature, such as the Umalusi (2020) report, confirms that assessments do not include all cognitive levels. It is further supported by belief \#7 of NVSD Curriculum Hub (2018) that assessment methods should make provision for leaners' diverse needs. The need for assessment that stimulates critical thinking is reinforced by the integrated course design model (Fink, 2003).

\subsection{Theme 2: Improper and inappropriate assessment}

The participants mentioned, for example, that assessments did not focus on the lesson/topic outcomes; some content/work that had to be assessed was not 
covered in lessons/class; learners were not actively involved; only one type of assessment activity was used in the assessment cycle and requirements were not taken into account when assessment tasks were set. Also that learners were provided with a "scope", which was basically the examination task (according to a 34-year-old female).

A 46-year-old female remarked that problems included "[assessments that are] above the age and development of learners; assessment that does not cover all cognitive levels and assessment that does not include a variety of skills".

A 26-year-old male participant pointed out the problem that "assessment ... discriminates [against] learners based on gender, race or religious beliefs, and ... [does not cater] for learners with barriers to learning".

According to a 35-year-old female, improper assessment is "when assessment does not address what has been covered in class; or when language used is too difficult for learners to understand".

Common remarks were that papers were based only on facts; assessment did not cater for all cognitive levels and tested only the academic/cognitive domain at the expense of other domains such as the affective and psychomotor domains; assessment showed no concern for learner diversity; and bias was allowed to influence the way that assessments were marked by the educator. Participants also mentioned lengthy assessments with weak motivation for learners, poor assessment standards, inadequate guidelines and poor instructions.

From the above-mentioned remarks, it is clear that the teachers have a good idea of what improper assessment is. This theme also links with belief \#10 (NVSD Curriculum Hub, 2018) that assessment and reporting practices and procedures must be beneficial to all learners, comprising those with special needs and those who are learning an additional language. Furthermore, the findings are in line with Fink's (2003) model, as well as statements by Shepard (2000) and Van der Nest et al. (2018), who indicate that teaching and learning must be aligned with learning goals, and that classroom tasks must align with learning goals and assessment criteria.

\subsection{Theme 3: How assessment is done and types of assessment}

According to a 34-year-old female participant, "[Assessment] is required to comply with the CAPS ... Each school is also expected to have their own assessment policy, based on the school's nature. Educators are also having to attend moderation sessions to make sure that the assessments are correct."

A 46-year-old female participant confirmed that "all formal tasks are moderated for quality assurance and are administered in a controlled environment. Postmoderation is done to ensure quality marking and to track learner progress".

A 34-year-old female stated, "The classes are big and you cannot always implement different assessment strategies/techniques. The use of first additional 
languages in classrooms is also an influential factor in assessment. Some assessment tasks expect learners and educators to use technology and schools do not have the resources (computers, projectors, etc.)."

The types of assessment mentioned by participants included mainly formal assessment, such as written or oral assessments, tests, assignments, class work, homework and projects, and informal assessment, for example quizzes and games.

Two forms of assessment are mainly used to assess learners' academic work, namely formative (continuous) assessment (based on assignments, projects and short/class tests) and summative assessment (written examinations at the end of a semester).

A 26-year-old male participant indicated that assessment was done "through formative assessment, e.g. tasks, assignments and exams". It was clear that this participant did not understand the difference between formative and summative assessment.

According to the findings, participants are aware of assessment policies and how moderation takes place. However, the teachers experience challenges, such as language barriers, overcrowded classrooms, a lack of technology, and confusion about the differences between summative and formative assessment.

Challenges are a reality. Assessment proof is used in assessment for learning whereby teachers adapt their teaching methods, and through which learners revise their learning tactics (Alberta Education, 2008; McNamee \& Chen, 2005). The finding that more formative assessment is required, confirms the importance of formative assessments as a necessary part of teaching and learning, as stated by Khan (2019).

\subsection{Theme 4: Assessment to enhance learning in the classroom and feedback}

A 34-year-old female participant used group work (groups of four) and YouTube videos: "Groups discussed different topics and made a poster with information. Each group got an opportunity to present their findings with the rest of the class with their poster. While groups are busy presenting they must take notes for themselves. The assessment activity [gave] the learners the opportunity to learn from [one another] and to explore the importance of independence."

In a reading comprehension, a 46-year-old female participant used the following techniques: "Ask a learner to read the topic; explain the topic to them; ask learners predictive questions; ask learners to underline important words - words which they think are telling them something about the topic; ask learners to circle new vocabulary; teach the meanings of words in context/teach learners to infer meanings of words; ask learners to sequence the events in the story; ask learners to summarise the text orally and later in written form. This helps learners to have a deeper understanding of the text. All learners were involved and the 
performance was good. They enjoyed comparing their responses with those of their peers."

A 34-year-old male Grade 7 Mathematics teacher stated, "I asked learners to design their own pattern. From their pattern they determined the expression and equation. They used their equation to draw a graph. By being actively involved in constructing their own graph and writing a conclusion, they understood how to bridge the concrete and abstract and better understand the concepts. I focus mostly [on] whether I can find a particular concept that most learners did not comprehend. I look for trends when marking. I'll discuss these with the whole class and learners respond very well because I would explain that concept differently from how I explained it initially to help them understand. More serious concerns I would discuss on a one-to-one base with the learners."

A 26-year-old male participant stated, "In one of my classes after a discussion lesson I previously had, I grouped the learners in groups of four and they had to prepare a presentation based on the previous lesson. The aim was to improve the learner's ability to present verbally and on paper what they learnt. We went through the assessment based on what they had presented, they did self-reflection on where they needed to improve and they seemed to be willing to take the feedback positively and to improve."

A 43-year-old female stated, "After they had written the June examination, I looked at each and every answer sheet of the Matrics to identify their challenges. I then conducted a diagnostic analysis to identify problem areas. I told them that the mark they had received meant that they knew something; they just needed to add to what they knew because for prelims we would only add two topics, both of which were a revision of Grade 11 work."

Other comments were that learners did corrections; they responded to things they did not understand; after assessment, adequate feedback was given to learners; and learners were then shown how to approach the questions in future assessments.

From the findings it was clear that teachers use group work, peer assessment, project-based learning, self-reflection and diagnostic analysis. They also alluded to the importance of proper feedback. The participants' remarks confirm the findings reported in the literature regarding types of assessment and the importance of proper feedback (see sections 2.1, 2.3 and 3). However, more differentiation in types of assessment may be used, as pointed out by Elton (2002).

\subsection{Theme 5: Assessment for learning}

A 34-year-old female participant said, "Through the assessment process, learning takes place and the core should be the development of learners. The objective of assessment is learning and then evaluating the shortcomings in the learning process." 
A 43-year-old female stated, "Assessment for learning is regarded as summative assessment. It is used to measure what the learners have learned at the end of every topic. In my subject, Accounting, learners are given daily activities after introduction of every topic. Activities are arranged from simple to complex. Informal assessment will then be given to prepare the learners for formal assessment. At the end of every term, the best learner in the subject is given a certificate."

A 54-year-old male participant stated that assessment for learning is "about measuring learners' progress in their learning. It is about systematically appraising learners' strengths and weaknesses ... and guiding them to achieve more. The [focus] is not on grades, but on the learning progress and how it can be enhanced".

A 33-year-old female said, "The teacher and learner work together to evaluate the learner's understanding of what she/he needs to learn to increase her/his knowledge... [Feedback is given] to improve a learner's performance."

A 26-year-old male stated, "Assessment for learning is about continuously monitoring whether learners are learning and understanding the content being taught. In my subject it needs to be used as a tool to monitor their understanding of theory ...."

Although most of the participants acknowledged that they understand what AFL is, one of the participants describes AFL as summative assessment. According to McNamee and Chen (2005), Burns (2005) and the NFER (2007) report, AFL is continuous (formative) assessment that allows teachers to appraise learners daily and adjust their teaching based on what the learners need in order to be successful.

\subsection{Theme 6: Main concerns and recommendations by participants}

The participants' general remarks and recommendations focused on three topics, namely school-related issues, university issues and departmental matters.

\subsubsection{School-based issues}

According to the participants, assessment in schools is not always implemented properly and might be rushed in an attempt to complete assessments before the end of the term. Educators should understand the purpose and the process of assessment. Furthermore, assessments should assess different competencies on different cognitive levels and make more use of Bloom's taxonomy.

Informal assessment must be of a high quality and prepare learners for formal tasks. Therefore, it should be monitored and corrections should be done after each assessment, irrespective of whether it is formal or informal. Assessment should help learners to succeed in their learning. It should promote confidence and motivation, while at the same time, provide opportunities for learners to improve their academic performance and progress well with their learning. Learners' grades should not be regarded as the most critical element of assessment; it should be aimed at improving learners' success in all domains of learning. Thus, every 
school management team should investigate, design and implement a proper assessment plan.

\subsubsection{University-based issues}

Participants highlighted that the current teaching practice is not enough to allow teachers to be exposed to what really happens in the school environment. As postPGCE students, they agree that ten weeks are not enough time. According to them, book knowledge can never prepare one for what really happens in the classroom. They stated that teachers definitely need more training in assessment because they struggle to set high-quality tasks or to use assessment tools, such as memoranda or rubrics, effectively. They suggested that more practical examples should be shown to student teachers in the form of lectures and videos. University training should further expose student teachers to the use of technology in the assessment system. Adequate training in the use of technology for assessment and other innovative assessment tools for learning were requested. It was suggested that a centre for such be established.

Universities need to involve schools more when planning the curriculum for teacher training. Universities should fill the gap between theory and practice. They should also consult and cooperate with the South African Council of Educators.

\subsubsection{Departmental matters}

Participants requested that workshops be arranged per subject and grade (and not in general), and be presented by more competent trainers.

\section{Conclusion}

This research was undertaken to investigate the experiences and knowledge of teachers who have already completed their postgraduate certificate in Education (PGCE) at a distance learning institution, and who have taught for at least five years. It is important for policy-makers and teacher training institutions to obtain a better understanding of the what and how of professional knowledge-building regarding assessment in the classroom. The research aim and objectives were met and the research proved answers to the capability of teacher's assessment in the classroom. The researcher recognises the limitations of the study, namely, that it reflects only one institution and a limited number of participants.

The picture that the researcher got from the participants was generally positive 12 of the 14 participants felt prepared to conduct effective assessment. Unfortunately, if we look at the reality of education in South Africa, there is also another side to this picture. Concerns were raised about the report on quality assurance by Umalusi and the results from the empirical data. The findings indicate inter alia that teachers need more assistance in classroom-based assessment. The need for training regarding assessment tools (for example, rubrics), and the use of technology and taxonomies, were highlighted. Assistance from school management teams in implementing an assessment plan, was also emphasised. Furthermore, an extension of the teaching practice period was indicated to prepare teachers for the reality. 
In light of the research results, it is recommended that educational programmes should have clear, explicitly stated purposes, which can guide assessment in the programmes. More practical examples, such as lecture videos, and taxonomies and rubrics should be used, and technology should be incorporated in assessment practices. More collaboration between stakeholders such as the South African Council of Educators, the DBE, universities and schools, is suggested. Teacher training should be holistic if it is to produce all-round reflective practitioners, who can adequately advance learner achievement in schools.

\section{Declaration of conflict of interest}

The research has no conflict of interest to declare.

\section{References}

Alberta Education. (2008). Types of Classroom Assessment. http://www.learnalberta.ca/content/mewa/html/assessment/types.html

Algonquin College. (2019). Qualities of Good Assessment Practices. Professor's Resource. https://www.algonquincollege.com/profres/assessing-learners/qualities-ofgood-assessment-practices/

Andrade, H. L., \& Cizek, G. J. (Ed). (2010). Handbook of formative assessment. New York: Routledge Taylor \& Francis Group.

Ayala, C. C., Shavelson R. J., Ruiz-Primo, M. A., Brandon, P. R., Yin, Y., Furtak, E. M., Young, D. B., \& Tomita, M. K. (2008). From formal embedded assessments to reflective lessons: The development of formative assessment studies. Applied Measurement in Education, 21(4), 315334. https://doi.org/10.1080/08957340802347787

Black, P., \& Wiliam, D. (2001). Inside the Black Box: Raising Standards Through Classroom Assessment. https://weaeducation.typepad.co.uk/files/blackbox-1.pdf

Booyse, C., Du Plessis, E. C., \& Maphalala, M. (2020). Curriculum studies in context. $4^{\text {th }}$ edition. Pretoria: Van Schaik.

Burns, M. (2005). Looking at how students reason. Educational Leadership, 63(3), 26-31.

Creswell, J. W. (2012). Research design: Educational research - planning, conducting and evaluating qualitative and quantitative research ( $4^{\text {th }}$ ed.) New York: Pearson.

DeLuca, C., \& Klinger, D. A. (2010). Assessment literacy development: Identifying gaps in teacher candidates' learning. Assessment in Education: Principles, Policy and Practice, 17(4), 419-138. https:/ / doi.org/10.1080/0969594X.2010.516643

DeLuca, C., Willis, J., Cowie, B., Harrison, C., Coombs, A., Gibson, A., \& Trask, S. (2019). Exploring the Complex Dynamics of Assessment Education in Teacher Education Across Four

Countries. https://www.frontiersin.org/articles/10.3389/feduc.2019.00132/full

Elton, L. (2002). Good assessment practice. Society for Research into Higher Education, 6, 106135.

Federation University. (2019). Types of feedback. https:// federation.edu.au/staff/learning-and-teaching/teachingpractice/feedback/types-of-feedback

Fink, D. L. (2003). A Self-Directed Guide to Designing Courses for Significant Learning. San Francisco: Jossey-Bass. https://inside.southernct.edu/sites/default/files/a/inside-southern/facultydevelopment/Self-Directed_Guide_to_Course_Design_-_Sept_10.pdf 
Frey, B. B. (2018). Feedback Intervention Theory. The SAGE Encyclopaedia of Educational Research, Measurement, and Evaluation. https://dx.doi.org/10.4135/ 9781506326139.n261

Friesen, S., Saar, C., Park, A., Marcotte, C., Hampshire, T., Martin, B., Brown, B., \& Martin, J. (2015). Focus on Inquiry. https://inquiry.galileo.org/ch3/assessment-withindiscipline-based-inquiry/

Hattie, J. (2016). Visible learning. http://visible-learning.org/john-hattie/

Khan, A. (2019). Meaning and Types of Assessment. Retrieved from https://www.toppr.com/bytes/types-of-assessment/

McMillan, J. H., \& Schumacher, M. (2014). Research in education: evidence-based inquiry. $7^{\text {th }}$ ed. Pearson New International Edition. Boston: Pearson.

McNamee, G. D., \& Chen, J. (2005). Dissolving the Line between Assessment and Teaching. Educational Leadership, 63(3), 72-76.

Measom, C. (2019). How to Be a Confident Teacher. http://work.chron.com/confidentteacher-1707.html

Mertens, D. M. (2010). Transformative Mixed Methods Research. Journal of Mixed Methods Research. New York: Sage Journals.

Ministry of Education. (2020). What is assessment for learning? http://assessment.tki.org.nz/Assessment-for-learning/Underlying-principlesof-assessment-for-learning/What-is-assessment-for-learning

National Foundation For Educational Research (NFER) Report. (2007). Getting started with Assessment for Learning. https://cambridge-community.org.uk/professionaldevelopment/gswafl/index.html

NFER. (2007). NFER position paper on assessment. https://www.nfer.ac.uk/nferposition-paper-on-assessment-2007

Ngulube, P. (2018). Overcoming the Difficulties Associated with Using Conceptual and Theoretical Frameworks in Heritage Studies. https://www.google.com/search?q=Ngulube\%2C+P.+2018.+Overcoming+the+ Difficulties+Associated+with+Using+Conceptual+and+Theoretical+Framework s+in+Heritage+Studies\&rlz=1C1CHZL_enZA778ZA778\&oq=Ngulube $\% 2 C+P$

NVSD Curriculum Hub. (2018). 10 Principles of Assessment. https://www.sd44.ca/District/Communicating/Assessment\%20Handbook/As sessment $\%$ 20Handbook\% 202018.pdf

Olivia, N. (2017). What is Trustworthiness in Qualitative Research? https://www.coursehero.com/file/p46d3mf/2017-Establishing-

Trustworthiness-in-Qualitative-Research

Oltmann, S. M. (2016). Qualitative interview: a methodological discussion of the interviewer and respondent contexts. Forum Qualitative Sozialforschung/Forum: Qualitative Social Research, 17(2), Art. $15 . \quad \mathrm{http} / / / \mathrm{nbn}$ resolving.de/urn:nbn:de:0114-fqs1602156

Pellegrino, J. W. (Ed). (2014). Developing Assessments for the Next Generation Science Standards Washington. The National Academies Press (NAP) publishes the reports of the National Academies of Sciences, Engineering, and Medicine.

Ruiz-Primo, M. A., Li, M., Wills, K., \& Sands, D. I. (2012). Developing and Evaluating Instructionally Sensitive Assessments in Science. Journal of Research in Science Teaching, 49(6),

691-712. https://www.researchgate.net/publication/258670010_Developing_and_Evalu ating_Instructionally_Sensitive_Assessments in_Science

Shepard, L. A. (2000). The role of classroom assessment in teaching and learning (CSE Technical Report 517). Los Angeles, CA: National Center for Research on Evaluation, Standards, and Student Testing, Graduate School of Education \& Information 
Studies, University of California. http://citeseerx.ist.psu.edu/viewdoc/download?doi=10.1.1.588.4254\&rep=rep1 \&type $=$ pdf

South Africa's Education Statistics. (2020). https://www.southafricanmi.com/educationstatistics.html

Schwartz-Shea, P., \& Yanow, D. (2020). Interpretivism. https://methods.sagepub.com/foundations/interpretivism

Umalusi. (2020). Quality assurance report. https://www.umalusi.org.za/wpcontent/uploads/2020/03/Nov-2019-DBE-QAA-Report-FINAL.pdf

Van der Nest, A., Long, C., \& Engelbrecht, J. (2018). South African Journal of Education, 38(1), 1-10. http://dx.doi.org/10.15700/saje.v38n1a1382

Wiley, C. R. H. (2008). Traditional teacher tests. In TL Good (ed). 21st Century education: A reference handbook (Vol. 1). Los Angeles, CA: Sage. 


\section{Appendix A}

\section{Dear student/teacher/HOD}

May I kindly request you to complete this questionnaire and send it back to me by the end of August.

The purpose is to understand teacher views/beliefs in relation to assessment practices.

Please answer the following open ended questions on ASSESSMENT in the classroom. Please write as much as you can to share with us your views about assessment methods, how well they work in your class, and what children gain from doing assessment. Your answers will be confidential and they will help us improve our teaching in our courses on curriculum studies.

1. Biographical information

\begin{tabular}{|l|l|l|}
\hline COUNTRY: & \multicolumn{3}{l|}{} \\
\hline AGE: & & \multicolumn{3}{l|}{} \\
\hline YEARS OF TEACHING EXPERIENCE: & $\mathrm{M}$ & $\mathrm{F}$ \\
\hline GENDER: & & \multicolumn{2}{|l|}{} \\
\hline
\end{tabular}

2. What is lacking in your assessment training, for example how to deal with discipline/multi-grade classes/diversity/technology/classmanagement?

3. Give 3 examples of improper and inappropriate assessment

4. Are you aware of the Assessment Policy and how familiar are you with it?

5. How is assessment of academic work of learners done?

6. Describe one opportunity where you used assessment to enhance learning in your classroom. This can be any level, any topic - note the plan you had to conduct this assessment, and how you intended the session to help children learn from the assessment. Describe the steps you followed and the detail of what transpired.

7. Note in detail your discussions with learners about the assessment, their performance - what you said, how they responded, and the discussions about the test in class among children.

8. Note here your reflections and views - what is assessment for learning about, and how should it be used in your subject?

9. Any other issues/comments/recommendations with regards to assessment?

10. Do you have any recommendations regarding university training for student teachers in order to equip and prepare them to enter the teaching profession after they have completed their qualification? 